Pacific Journal of Mathematics

RANGE OF GATEAUX DIFFERENTIABLE OPERATORS AND 


\title{
RANGE OF GATEAUX DIFFERENTIABLE OPERATORS AND LOCAL EXPANSIONS
}

\author{
Jong Sook BaE AND SANGsuk Yie
}

Let $X$ and $Y$ be Banach spaces, and $P: X \rightarrow Y$ a Gateaux differentiable operator having closed graph. Suppose that there is a continuous function $c:[0, \infty) \rightarrow(0, \infty)$ satisfying

$$
d P_{x}(\bar{B}(0 ; 1)) \supseteq \bar{B}(0 ; c(\|x\|)) .
$$

Then it is shown that for any $K>0$ (possibly $K=\infty), P(B(0 ; K)$ ) contains $B\left(P(0) ; \int_{0}^{K} c(s) d s\right)$. Similar results are obtained for local expansions and locally strongly $\phi$-accretive operators. These results extend a number of known theorems by giving the precise geometric estimations for normal solvability of $P x=y$.

1. Introduction. Let $P$ be a nonlinear operator from a Banach space $X$ into a Banach space $Y$. Many authors (see [3], [4], [6], [7], [10], [12], [13], [14] and [15]) have studied solvability of the equation $P x=y$, for $y \in Y$, a considerable number of which involve local or infinitesimal assumptions on the operator $P$, by showing that $P$ is surjective. However, in many cases, in general $P$ need not be surjective, although for some $y \in Y$, the equation $P x=y$ is solvable. For example, let $P$ be a Gateaux differentiable operator having closed graph such that for each $x \in X$,

$$
d P_{x}(\bar{B}(0 ; 1)) \supseteq \bar{B}(0 ; c(\|x\|))
$$

where $c:[0, \infty) \rightarrow(0, \infty)$ is a continuous function. In [13], Ray and Walker showed that $P$ is surjective, where $c$ is nonincreasing and $\int_{0}^{\infty} c(s) d s=\infty$. However, although $c$ is not nonincreasing and $\int_{0}^{\infty} c(s) d s$ $<\infty$, intuitively we may expect that for any $K>0$ (possibly $K=\infty$ ), $P(B(0 ; K))$ contains $B\left(P(0) ; \int_{0}^{K} c(s) d s\right)$ by considering an elementary integral equation, so that for any $y \in B\left(P(0) ; \int_{0}^{K} c(s) d s\right) \subseteq Y, P x=y$ has a solution $x$ in $B(0 ; K) \subseteq X$.

In this paper, we show that the fact mentioned above holds, and such an idea can be applied to local expansions and locally strongly $\phi$-accretive operators similarly. For this purpose, in $\$ 2$, we give a fixed point theorem which is a basic tool in proving theorems in $\S 3$. And in $\S 3$, we apply this result to nonlinear operators. 
2. A fixed point theorem. In this section we give a fixed point theorem which is a basic tool in proving theorems in the next section. Actually our theorem is based on the following well-known Caristi-KirkBrowder fixed point theorem [5], which is an equivalent formulation of Ekeland's minimization theorem [8, 9].

THEOREM 2.1. Let $(M, d)$ be a complete metric space and $\phi$ be a lower semicontinuous (l.s.c.) function from $M$ to $R \cup\{\infty\}$, $\not \equiv \infty$, bounded from below. Let $g$ be a selfmap of $M$ satisfying,

$$
d(x, g(x))+\phi(g(x)) \leq \phi(x)
$$

for all $x \in M$. Then $g$ has a fixed point in $M$.

THEOREM 2.2. Let $(M, d)$ be a complete metric space, and $\psi$ be a l.s.c. function from $M$ into $[0, \infty)$. Let $c$ be a continuous nonincreasing function from $[0, \infty)$ into $(0, \infty)$, and let $x_{0} \in M$ be fixed. Further suppose that there exist $z \in M$ and $K>0$ ( possibly $K=\infty$ ) satisfying $\int_{d\left(x_{0}, z\right)}^{K} c(s) d s \geq$ $\psi(z)$ (when $K=\infty, \int_{d\left(x_{0}, z\right)}^{\infty} c(s) d s>\psi(z)$ ). If $g$ is a selfmap of $M$ satisfying

$$
c\left(d\left(x_{0}, x\right)\right) d(x, g(x)) \leq \psi(x)-\psi(g(x))
$$

whenever $x \in M$ with $\int_{d\left(x_{0}, x\right)}^{K} c(s) d s \geq \psi(x)$, then $g$ has a fixed point in $M$.

If $\int_{0}^{\infty} c(s) d s=\infty$, then Theorem 2.2 is the same as Theorem 2.1 of [13], which is actually equivalent to Ekeland's theorem [8, 9] (see [11]). Theorem 2.2 is a slightly extended version of Theorem 2.1, but they are actually equivalent in logic. The advantage of Theorem 2.2 is that we need not examine the inequality (2.2) for all $x \in M$, that is, if for suitable $x \in M$ (2.2) holds, we have the desired conclusion. In fact, in Theorem 2.1, by putting $A=\{x \in M ; d(x, z) \leq \phi(z)-\phi(x)\}$ for some $z \in M$ with $\phi(z)<\infty$, we have $g(A) \subseteq A$ and $g$ has a fixed point in $A$. Also this fact gives the basic idea of the proof of Theorem 2.2.

Proof of Theorem 2.2. Now we construct a new function $\phi: M \rightarrow$ $[0, \infty]$, which is $\not \equiv \infty$, 1.s.c. and satisfies (2.1), so that by applying Theorem 2.1, $g$ has a fixed point in $M$. If $K=\infty$ and $\int_{0}^{\infty} c(s) d s=\infty$, then Park and Bae [11] showed that the equality

$$
\int_{d\left(x_{0}, x\right)}^{d\left(x_{0}, x\right)+\phi(x)} c(s) d s=\psi(x)
$$

gives $\phi$ which is a desired one. Therefore we may assume that $K<\infty$ (if $K=\infty$ and $\int_{0}^{\infty} c(s) d s<\infty$, then the similar method well do). Now 
define $\phi$ as follows: if $\int_{d\left(x_{0}, x\right)}^{K} c(s) d s \geq \psi(x)$, then put $\phi(x)$ satisfying $\int_{d\left(x_{0}, x\right)}^{d\left(x_{0}, x\right)+\phi(x)} c(s) d s=\psi(x)$, and if $\int_{d\left(x_{0}, x\right)}^{K} c(s) d s<\psi(x)$, then put $\phi(x)$ $=\infty$.

To show that $\phi$ is 1.s.c., let $x_{n} \rightarrow x$ and $\lim \phi\left(x_{n}\right)=t$. If $t=\infty$, then there is nothing to prove, so that we may assume that $t<\infty$. Now we can choose a subsequence $\left\{x_{n_{k}}\right\}$ such that $\lim \phi\left(x_{n_{k}}\right)=t$. Then since $\lim d\left(x_{n}, x_{0}\right)=d\left(x_{0}, x\right)$, we have

$$
\begin{aligned}
\int_{d\left(x_{0}, x\right)}^{d\left(x_{0}, x\right)+t} c(s) d s & =\lim \int_{d\left(x_{0}, x\right)}^{d\left(x_{0}, x\right)+\phi\left(x_{n_{k}}\right)} c(s) d s \\
& =\lim \psi\left(x_{n_{k}}\right) \geq \psi(x),
\end{aligned}
$$

and $d\left(x_{0}, x\right)+t=\lim \left(d\left(x_{0}, x\right)+\phi\left(x_{n_{k}}\right)\right) \leq K$. Therefore $\phi(x) \leq t$, and consequently $\phi$ is 1.s.c.

To prove that $\phi$ satisfies (2.1), it suffices to prove that

$$
d(x, y)+\phi(y) \leq \phi(x)
$$

whenever $\int_{d\left(x_{0}, x\right)}^{K} c(s) d s \geq \psi(x)$ and

$$
c\left(d\left(x_{0}, x\right)\right) d(x, y) \leq \psi(x)-\psi(y),
$$

since if $\phi(x)=\infty$, then (2.1) is trivially true. Suppose that the latter case holds. Since $c$ is nonincreasing,

$$
\int_{d\left(x_{0}, x\right)}^{d\left(x_{0}, x\right)+d(x, y)} c(s) d s \leq c\left(d\left(x_{0}, x\right)\right) d(x, y) .
$$

Therefore by assuming $\phi(y)<\infty$, we have

$$
\begin{aligned}
\int_{d\left(x_{0}, x\right)}^{d\left(x_{0}, x\right)+d(x, y)} c(s) d s \leq & \int_{d\left(x_{0}, x\right)}^{d\left(x_{0}, x\right)+\phi(x)} c(s) d s \\
& -\int_{d\left(x_{0}, y\right)}^{d\left(x_{0}, y\right)+\phi(y)} c(s) d s .
\end{aligned}
$$

Since $d\left(x_{0}, y\right) \leq d\left(x_{0}, x\right)+d(x, y)$ and $c$ is nonincreasing,

$$
\begin{aligned}
\int_{d\left(x_{0}, x\right)}^{d\left(x_{0}, x\right)+d(x, y)} c(s) d s & +\int_{d\left(x_{0}, x\right)+d(x, y)}^{d\left(x_{0}, x\right)+d(x, y)+\phi(y)} c(s) d s \\
\leq & \int_{d\left(x_{0}, x\right)}^{d\left(x_{0}, x\right)+\phi(x)} c(s) d s,
\end{aligned}
$$

which shows that $d(x, y)+\phi(y) \leq \phi(x)$. In the above case actually $\phi(y)<\infty$. To see this, suppose that $\phi(y)=\infty$. Then we can find $\varepsilon>0$ such that $\int_{d\left(x_{0}, y\right)}^{K+\varepsilon} c(s) d s \leq \psi(y)$, and hence the above inequalities give

$$
\int_{d\left(x_{0}, x\right)}^{K+\varepsilon} c(s) d s \leq \int_{d\left(x_{0}, x\right)}^{d\left(x_{0}, x\right)+\phi(x)} c(s) d s,
$$

which is a contradiction to the fact that $\phi(x)<\infty$. 
As a direct consequence of Theorem 2.2, we have the following Corollary by putting $c$ is constant.

COROllary 2.3. Let $(M, d)$ be a complete metric space, $\phi$ a l.s.c. function from $M$ into $[0, \infty)$ and let $x_{0} \in M$ be fixed. Suppose that there exist $z \in M, K>0$ and $c>0$ such that $c\left(K-d\left(x_{0}, z\right)\right)=\phi(z)$. If $g$ is a selfmap of $M$ satisfying

$$
c d(x, g(x)) \leq \phi(x)-\phi(g(x))
$$

for all $x \in M$ with $c\left(K-d\left(x_{0}, x\right)\right) \geq \phi(x)$, then $g$ has a fixed point in $M$.

Note that when $z=x_{0}$, Corollary 2.3 is the same as Theorem 2.1 by considering the set $A=\{x \in M ; c d(x, z) \leq \phi(z)-\phi(x)\}$, and $g(A) \subseteq$ A.

3. Range of operators. In this section we apply Theorem 2.2 to Gateaux differentiable operators, local expansions and locally strongly $\phi$-accretive operators. We begin with the Gateaux differentiable operators.

Let $X$ and $Y$ be Banach spaces, and $P$ a mapping from an open subset $D$ of $X$ to $Y$. We say that $P$ is Gateaux differentiable if, for each $x \in D$, there is a function $d P_{x}: X \rightarrow Y$ satisfying

$$
\lim _{t \rightarrow 0^{+}} \frac{P(x+t y)-P(x)}{t}=d P_{x}(y), \quad y \in X .
$$

Easy examples show that Gateaux differentiable operators need not be continuous. Note that we do not require that $d P_{x}$ is linear. However, it follows from the definition that $d P_{x}$ is homogeneous, that is, $d P_{x}(t y)=$ $t d P_{x}(y)$ for all $t \geq 0$.

We say that an operator $P: D \rightarrow Y$ has closed graph if $\left\{x_{n}\right\} \subseteq D$ with $x_{n} \rightarrow x \in D$ and $P x_{n} \rightarrow y$ as $n \rightarrow \infty$, it follows that $P x=y$. We denote by $B(w ; r)$ the set $\{y ;\|y-w\|<r\}$, and $\bar{B}(w ; r)$ its closure. Also conveniently we set $B(w ; \infty)=X$ (if $w \in X)$.

Now we state our first theorem. The techniques used here are analogous to those of Ray and Walker [13].

Theorem 3.1. Let $X$ and $Y$ be Banach spaces, and $P$ a Gateaux - differentiable mapping from $B(0 ; K) \subseteq X$ to $Y$ having closed graph, where $K>0$. Let $c:[0, K) \rightarrow(0, \infty)$ be a continuous nonincreasing function for which, for each $x \in B(0 ; K)$,

$$
d P_{x}(\bar{B}(0 ; 1)) \supseteq \bar{B}(0 ; c(\|x\|)) .
$$

Then $P(B(0 ; K))$ contains $B\left(P(0) ; \int_{0}^{K} c(s) d s\right)$. 
We remark that Theorem 3.1 shows that actually $P$ is an open mapping, therefore it gives Theorem 3.2 of Cramer and Ray [6] and Theorem 2.2 of Ray [12]. But in order to prove these they used the maximal principle of Brezis and Browder [2], however our basic tool is Theorem 2.2, which is an equivalent formulation of Ekeland [8, 9]. Also Theorem 3.1 can be compared with Theorem 3.1 of Ray and Walker [13] and Theorem 2.4 of [12], which treat only the case $K=\infty$ and $\int_{0}^{\infty} c(s) d s$ $=\infty$; in this case Theorem 3.1 is that of [13], which extends Theorem 4 of [15]. Moreover, in Theorem 3.4 we will show that the function $c$ need not be nonincreasing. The advantage of our formulation here is that our results contain the range of operators explicitly and we do not assume that the domain of $P$ is the whole space $X$.

Proof of Theorem 3.1. Let $w \in B\left(P(0) ; \int_{0}^{K} c(s) d s\right)$, that is, $\| w-$ $P(0) \|<\int_{0}^{K} c(s) d s$. We can choose $0<q<1$ satisfying

$$
(1-q)^{-1}\|w-P(0)\|<\int_{0}^{K} c(s) d s .
$$

Also we can take a sufficiently small $\varepsilon>0$ satisfying

$$
(1-q)^{-1}\|w-P(0)\| \leq \int_{0}^{K-2 \varepsilon} c(s) d s .
$$

Define a new metric $\rho$ on the set $M=\bar{B}(0 ; K-\varepsilon)$ by

$$
\rho(x, y)=\max \left\{\|x-y\|, c(0)^{-1}(1+q)^{-1}\|P(x)-P(y)\|\right\} .
$$

Since $P$ has closed graph, $(M, \rho)$ is a complete metric space. Set $\psi(x)=$ $(1-q)^{-1}\|P x-w\|$, so that $\psi:(M, \rho) \rightarrow[0, \infty)$ is continuous and $\psi(0)$ $\leq \int_{0}^{K-2 \varepsilon} c(s) d s$.

Now we claim that $w \in P(\bar{B}(0 ; K-2 \varepsilon))$. We proceed by contradiction and suppose that $w \notin P(\bar{B}(0 ; K-2 \varepsilon))$. For any $x \in$ $M \backslash \bar{B}(0 ; K-2 \varepsilon)$, we have $\int_{\rho(0, x)}^{K-2 \varepsilon} c(s) d s<0 \leq \psi(x)$, since $\rho(0, x) \geq$ $\|x\|>K-2 \varepsilon$. In this case set $g(x)=0(\neq x)$. For $x \in \bar{B}(0 ; K-2 \varepsilon)$, set $v=\|w-P x\|^{-1} c(\|x\|)(w-P x)$. Then by (3.1), there is a $u \in$ $\bar{B}(0 ; 1) \subseteq X$ such that $d P_{x}(u)=v$ and so, if $h=c(\|x\|)^{-1}\|w-P x\| u$, then $d P_{x}(h)=w-P x$. Since $P$ is Gateaux differentiable, we may choose $t \in(0,1]$ so small that $x+t h \in \bar{B}(0 ; K-\varepsilon)=M$ and

$$
\left\|P(x+t h)-P(x)-t d P_{x}(h)\right\| \leq q t\|w-P x\| .
$$

By setting $g(x)=x+t h$, this implies $g(x) \neq x$ and

$$
\|P(g(x))-P(x)-t(w-P x)\| \leq q t\|w-P x\|
$$


and

$$
c(\|x\|)\|g(x)-x\| \leq t\|w-P x\| .
$$

From (3.3), we have

$$
\|P(g(x))-P(x)\| \leq(1+q) t\|w-P x\|
$$

and

$$
\|P(g(x))-w\|-(1-t)\|P x-w\| \leq q t\|w-P x\|,
$$

which implies

$$
(1-q) t\|P x-w\| \leq\|P x-w\|-\|P(g(x))-w\| .
$$

Combining (3.5) and (3.6), we have

$$
(1+q)^{-1}\|P(g(x))-P(x)\| \leq \psi(x)-\psi(g(x))
$$

and combining (3.4) and (3.6), we get

$$
c(\|x\|)\|g(x)-x\| \leq \psi(x)-\psi(g(x)) .
$$

Here we may assume that the domain of $c$ is $[0, \infty)$ by putting $c(s)=c(K-2 \varepsilon)$ when $s>K-2 \varepsilon$ without affecting our argument of the proof. Now if $\rho(x, g(x))=\|x-g(x)\|$, then, since $\|x\| \leq \rho(0, x)$, (3.8) gives (2.2), while if $\rho(x, g(x))=c(0)^{-1}(1+q)^{-1}\|P(x)-P(g(x))\|$, then, since $c$ is nonincreasing,

$$
\begin{aligned}
c(\|x\|) \rho(x, g(x)) & =\frac{c(\|x\|)}{c(0)(1+q)}\|P x-P(g(x))\| \\
& \leq(1+q)^{-1}\|P(x)-P(g(x))\| \leq \psi(x)-\psi(g(x))
\end{aligned}
$$

by (3.7), so again (2.2) holds. Thus by Theorem $2.2, g$ has a fixed point in $M$, a contradiction, and hence consequently $w \in P(\vec{B}(0 ; K-2 \varepsilon)) \subseteq$ $P(B(0 ; K))$.

Analogous estimations for range of local expansions can be stated by the following theorem, which gives an extended version of Theorem 3.3 of [13] which also generalizes a result of Browder ([4], Theorem 4.10).

THEOREM 3.2. Let $X$ and $Y$ be Banach spaces, $P$ an open mapping from $B(0 ; K) \subseteq X(K>0)$ to $Y$ having closed graph, and let $c:[0, K) \rightarrow(0, \infty)$ be a continuous nonincreasing function. Suppose for each $x \in B(0 ; K)$, there is an $\varepsilon>0$ such that, if $y \in B(x ; \varepsilon) \cap B(0 ; K)$, then

$$
c(\max \{\|x\|,\|y\|\})\|x-y\| \leq\|P x-P y\| .
$$

Then $P(B(0 ; K))$ contains $B\left(P(0) ; \int_{0}^{K} c(s) d s\right)$. 
Proof. Let $w \in B\left(P(0) ; \int_{0}^{K} c(s) d s\right)$, that is, $\|w-P(0)\|<\int_{0}^{K} c(s) d s$. Then we can choose $\varepsilon_{1}>0$ so small that $\|w-P(0)\| \leq \int_{\varepsilon_{1}}^{K-\varepsilon_{1}} c(s) d s$ holds.

Introduce a new metric $\rho$ on the set $M=\bar{B}\left(0 ; K-\varepsilon_{1}\right)$ by setting $\rho(x, y)=\max \left\{\|x-y\|, c(0)^{-1}\|P x-P y\|\right\}$, so $(M, \rho)$ is complete, and set $\psi(x)=\|w-P x\|$. Let $\bar{c}(s)=c\left(s+\varepsilon_{1}\right)$. Then $\psi(0) \leq \int_{\varepsilon_{1}}^{K-\varepsilon_{1}} c(s) d s=$ $\int_{0}^{K-2 \varepsilon_{1}} \bar{c}(s) d s$. Now we claim that $w \in P\left(\bar{B}\left(0 ; K-2 \varepsilon_{1}\right)\right)$. As in the proof of Theorem 3.1, we suppose $w \notin P\left(\bar{B}\left(0 ; K-2 \varepsilon_{1}\right)\right)$ and obtain a contradiction. Now we define a mapping $g: M \rightarrow M$ by setting $g(x)=0$ $(\neq x)$ when $x \in M \backslash \bar{B}\left(0 ; K-2 \varepsilon_{1}\right)$; note that in this case $\int_{\rho(0, x)}^{K-2 \varepsilon_{1}} \bar{c}(s) d s$ $<0 \leq \psi(x)$, and if $x \in \bar{B}\left(0 ; K-2 \varepsilon_{1}\right)$, then choose $\varepsilon>0$ so small that $\varepsilon \leq \varepsilon_{1}$ and (3.9) holds. Actually the condition (3.9) can be replaced by the condition that if $\|x-y\|<\varepsilon$, then

$$
\bar{c}(\|x\|)\|x-y\| \leq\|P x-P y\| \text {. }
$$

Since $P$ is an open mapping

$$
P(B(x ; \varepsilon)) \cap\{t P x+(1-t) w ; 0 \leq t<1\} \neq \varnothing
$$

and hence there is a $g(x) \in B(x ; \varepsilon)$ such that $P(g(x)) \in\{t P x+$ $(1-t) w ; 0 \leq t<1\}$, so that $g(x) \neq x$ and $g(x) \in M$. Since $\|P(g(x))-P(x)\|=\|P x-w\|-\|P(g(x))-w\|=\psi(x)-\psi(g(x))$, it follows that

$$
\bar{c}(\|x\|)\|g(x)-x\| \leq \psi(x)-\psi(g(x))
$$

and

$$
\bar{c}(\|x\|) c(0)^{-1}\|P(g(x))-P x\| \leq \psi(x)-\psi(g(x)),
$$

and hence (2.2) holds by assuming that the domain of $\bar{c}$ is $[0, \infty)$ as in the proof of Theorem 3.1. Thus by Theorem 2.2, $g$ has a fixed point in $M$, which contradicts to the construction of $g(x)$.

Theorem 3.2 can be applied to the range of locally strongly $\phi$-accretive operators. Let $X$ and $Y$ be Banach spaces with $Y^{*}$ the dual of $Y$, and let $\phi: X \rightarrow Y^{*}$ be a mapping such that

$$
\begin{aligned}
& \phi(X) \text { is dense in } Y^{*}, \text { for each } x \in X \text { and each } \xi \geq 0 \\
& \|\phi(x)\| \leq\|x\| \text { and } \phi(\xi x)=\xi \phi(x) .
\end{aligned}
$$

A mapping $P$ from $X$ to $Y$ is said to be strongly $\phi$-accretive if there exists a constant $c>0$ such that, for any $x, y \in X$,

$$
(P x-P y, \phi(x-y)) \geq c\|x-y\|^{2} \text {. }
$$


The $\phi$-accretive mappings were introduced in an effort to unify the theories for monotone mappings (when $Y=X^{*}$ ) and for accretive mappings (when $Y=X$ ). Many authors (see [3], [4], [7], [10], [13], [16] and [17]) have studied domain invariance or surjectivity of accretive operators. The following theorem gives an improvement of Theorem 4.11 of [4], Corollary 2.2 of [6] and Theorem 3.4 of [13].

Theorem 3.3. Let $X$ and $Y$ be Banach spaces, and $P$ an open mapping from $B(0 ; K) \subseteq X(K>0)$ to $Y$ having closed graph. Let $c:[0, K) \rightarrow$ $(0, \infty)$ be continuous nonincreasing for which, for any $x \in B(0 ; K)$, there is an $\varepsilon>0$ such that for every $y \in B(x ; \varepsilon) \cap B(0 ; K)$,

$$
(P x-P y, \phi(x-y)) \geq c(\max \{\|x\|,\|y\|\})\|x-y\|^{2} .
$$

Then $P(B(0 ; K))$ contains $B\left(P(0) ; \int_{0}^{K} c(s) d s\right)$.

Proof. It is easy to show that (3.10) implies (3.9), so that Theorem 3.3 follows from Theorem 3.2.

In Theorem 3.3, if $P$ is locally lipschitzian, and if $Y$ can be renormed so that $Y$ is Frechet differentiable and $Y^{*}$ is strictly convex, that is, the duality mapping $J: Y \rightarrow Y^{*}$ is single-valued and continuous, then Downing and Ray [7] show that $P$ is automatically an open mapping. Also if $Y=X$ and $\phi$ is the duality mapping, and if $P$ is continuous, then $P$ is an open mapping by [16] and [17]. Also Theorem 3.3 can be applied to multivalued locally strongly $\phi$-accretive mappings as in [7].

Note that the continuity of $c$ in Theorem 2.2 and Theorems 3.1-3.3 can be replaced by the piecewise continuity of $c$ without affecting results of those theorems.

Simple geometric intuition and integral equation suggest that $c$ need not be nonincreasing in Theorems 3.1-3.3. Actually by using easy geometric estimation we can prove that such a condition can be removed in the following Theorem 3.4. In fact, Torrejon [17] proved that in Theorem 3.2, if $K=\infty$ and $\int_{0}^{\infty} c(s) d s=\infty$, then the condition that $c$ is nonincreasing is not necessary.

THEOREM 3.4. The conclusions of Theorems 3.1-3.3 hold without the assumption that $c$ is nonincreasing.

Proof. We may assume that $P(0)=0$ after parallel transformation. Since $c$ is continuous, for any given $\varepsilon>0$, there is a partition

$$
0=K_{0}<K_{1}<\cdots<K_{n}<K
$$


of $[0, K]$ such that by putting

$$
m_{i}=\inf \left\{c(s) ; K_{i-1} \leq s \leq K_{i}\right\}, \quad 1 \leq i \leq n,
$$

the inequality

$$
\sum_{i=1}^{n} m_{i}\left(K_{i}-K_{i-1}\right) \geq \int_{0}^{K} c(s) d s-\varepsilon
$$

holds. Now we will prove that $P\left(B\left(0 ; K_{n}\right)\right)$ contains $B\left(0 ; \int_{0}^{K} c(s) d s-\varepsilon\right)$, and hence we complete the proof since $\varepsilon$ is arbitrary. For this purpose, it suffices to prove that for any given $w \in Y$ with $\|w\|=1$,

$$
\text { the segment }\left\{t w ; 0 \leq t<M_{k}\right\} \subseteq P\left(B\left(0 ; K_{k}\right)\right)
$$

for any $k, 1 \leq k \leq n$, where

$$
M_{k}=\sum_{i=1}^{k} m_{i}\left(K_{i}-K_{i-1}\right) \text {. }
$$

Then for $k=n$, we have $\left\{t w ; 0 \leq t<M_{n}\right\} \subseteq P\left(B\left(0 ; K_{n}\right)\right)$, and this implies $B\left(0 ; \int_{0}^{K} c(s) d s-\varepsilon\right) \subseteq B\left(0 ; M_{n}\right) \subseteq P\left(B\left(0 ; K_{n}\right)\right)$.

First note that if $c$ is nonincreasing (in particular, $c$ is a constant function), then the theorem holds by Theorems 3.1-3.3. Therefore if $k=1$, then (3.11) is trivially true. Suppose that (3.11) is not true for some $k \geq 2$, and $k$ is the smallest integer for which (3.11) does not hold. Then there is a $t_{0}$ with $M_{k-1} \leq t_{0}<M_{k}$ such that $t_{0} w \notin P\left(B\left(0 ; K_{k}\right)\right)$, but $\left\{t w ; 0 \leq t<M_{k-1}\right\} \subseteq P\left(B\left(0 ; K_{k-1}\right)\right)$. Now choose an $\varepsilon_{1}>0$ so small that $\varepsilon_{1}<M_{k}-t_{0}$. Take $r>0$ such that $m_{k} r<\varepsilon_{1} / 4$, and set $m=$ $\min \left\{m_{1}, m_{2}, \ldots, m_{k}\right\}>0$. Then note that, by Theorems 3.1-3.3,

$$
\text { if }\|x\|<K_{k-1}+r \text {, then } P(B(x ; r)) \supseteq B(P(x) ; m r)
$$

and

$$
\text { if } \begin{aligned}
K_{k-1}+r \leq\|x\| \leq K_{k}-r, & \\
& \text { then } P(B(x ; r)) \supseteq B\left(P(x) ; m_{k} r\right) .
\end{aligned}
$$

(3.12) and (3.13) are possible, since $P$ satisfies the conditions of Theorems $3.1-3.3$, respectively, by setting $c(s)=m$ in case (3.12) and $c(s)=m_{k}$ in case (3.13) on $B(x ; r)$.

Also take $\varepsilon_{2}>0$ so small that $\varepsilon_{2}<\min \left\{\varepsilon_{1} / 4, r m\right\}$. Then since $\{t w$; $\left.0 \leq t<M_{k-1}\right\} \subseteq P\left(B\left(0 ; K_{k-1}\right)\right)$, we can take $x_{1} \in B\left(0 ; K_{k-1}\right)$ so that $P x_{1}=t_{1} w$, where $t_{1}=M_{k-1}-2^{-1} \varepsilon_{2}$. Also by (3.12), we can choose $x_{2} \in B\left(x_{1} ; r\right)$ so that $P x_{2}=t_{2} w$, where $t_{2}=t_{1}+r m-2^{-2} \varepsilon_{2}$. Continue this process, we assume that $x_{j}$ and $t_{j}$ be chosen for $j \geq 2$ with $\left\|x_{i}\right\| \leq K_{k}$ $-r$ for all $i \leq j$. Then if $\left\|x_{j}\right\|<K_{k-1}+r$, then by (3.12) there exists 
$x_{j+1} \in B\left(x_{j} ; r\right)$ such that $P x_{j+1}=t_{j+1} w$, where $t_{j+1}=t_{j}+r m-$ $2^{-j-1} \varepsilon_{2}$, and if $K_{k-1}+r \leq\left\|x_{j}\right\| \leq K_{k}-r$, then by (3.13) there exists $x_{j+1} \in B\left(x_{j} ; r\right)$ such that $P x_{j+1}=t_{j+1} w$, where $t_{j+1}=t_{j}+r m_{k}$ $2^{-j-1} \varepsilon_{2}$. We can continue the above process unless $\left\|x_{j}\right\|>K_{k}-r$. Now we claim that there is a $j$ such that $t_{j} \leq t_{0}<t_{j+1}$ with $\left\|x_{i}\right\| \leq K_{k}-r$ for all $i \leq j$, so that $t_{0} w \in P\left(B\left(x_{j} ; r\right)\right) \subseteq P\left(B\left(0 ; K_{k}\right)\right)$, which is a contradiction.

To prove our claim, suppose that $\left\|x_{j}\right\| \leq K_{k}-r$ for all $j=1,2, \ldots$. Then for $j \geq 2$, we have

$$
\begin{aligned}
t_{j} & \geq t_{j-1}+r m-2^{-j} \varepsilon_{2} \quad\left(\text { since } m \leq m_{k}\right) \\
& \vdots \\
& \geq t_{1}+(j-1) r m-\left(2^{-2}+\cdots+2^{-j}\right) \varepsilon_{2} \\
& \geq M_{k-1}+(j-1) r m-\varepsilon_{2} \quad\left(\text { since } t_{1}=M_{k-1}-2^{-1} \varepsilon_{2}\right) .
\end{aligned}
$$

Since $r m>0$, for some sufficiently large $j$, we can have $t_{0}<t_{j+1}$. Also since the sequence $\left\{t_{i}\right\}$ is increasing, our claim is proved. Now suppose that for some $j,\left\|x_{j+1}\right\|>K_{k}-r$ and $\left\|x_{i}\right\| \leq K_{k}-r$ for all $i \leq j$. Since $\left\|x_{i}-x_{i+1}\right\|<r(1 \leq i \leq j)$ and $r m_{k}<\varepsilon_{1} / 4 \leq\left(M_{k}-M_{k-1}\right) / 4$, we have $4 r<K_{k}-K_{k-1}$, so that there is a $j_{0}$ with $1 \leq j_{0}<j-1$ satisfying $\left\|x_{j_{0}}\right\|<K_{k-1}+r$ and $K_{k-1}+r \leq\left\|x_{i}\right\| \leq K_{k}-r$ for all $j_{0}+1 \leq i \leq j$. Then we have $\left\|x_{j+1}-x_{j_{0}+1}\right\|>K_{k}-K_{k-1}-3 r$, and hence $\left(j-j_{0}\right) r>$ $K_{k}-K_{k-1}-3 r$. Note that $t_{i}<t_{i+1}$ for all $1 \leq i \leq j$, and $t_{i+1}=t_{i}+$ $r m_{k}-2^{-i-1} \varepsilon_{2}$ for all $j_{0}+1 \leq i \leq j$. Therefore we have

$$
\begin{aligned}
t_{j+1} & =t_{j}+r m_{k}-2^{-j-1} \varepsilon_{2} \\
& \vdots \\
& >t_{j_{0}+1}+\left(j-j_{0}\right) r m_{k}-2^{-j_{0}} \varepsilon_{2} \\
& >t_{1}+\left(K_{k}-K_{k-1}-3 r\right) m_{k}-2^{-j_{0}} \varepsilon_{2} \\
& >M_{k-1}+M_{k}-M_{k-1}-3 r m_{k}-\varepsilon_{2} \\
& >M_{k}-\varepsilon_{1}>t_{0} .
\end{aligned}
$$

so that we complete the proof.

We list here one final conclusion as the following

THeOREM 3.5. Let $X$ and $Y$ be Banach spaces, and $P$ an operator from $X$ to $Y$ having closed graph. Let $c:[0, \infty) \rightarrow(0, \infty)$ be a continuous function for which one of the following conditions holds.

(a) $P$ is Gateaux differentiable and for each $x \in X$, (3.1) holds. 
(b) $P$ is an open mapping and for each $x \in X$, there is an $\varepsilon>0$ such that for every $\|x-y\|<\varepsilon$, (3.9) holds.

(c) $P$ is an open mapping and for each $x \in X$, there is an $\varepsilon>0$ such that for every $\|x-y\|<\varepsilon$, (3.10) holds.

Then for any $K>0$ (possibly $K=\infty), \quad P(B(0 ; K)$ ) contains $B\left(P(0) ; \int_{0}^{K} c(s) d s\right)$, in particular, if $\int_{0}^{\infty} c(s) d s=\infty$, then $P$ is surjective.

As a final remark, the condition (3.2) can be applied to the following extended version of Theorem 2 of [14]. The proof of the following theorem follows from (3.2) and Lemma of [14]. There is no significant variation in the proof, and so we omit it.

THEOREM 3.6. Let $X$ and $Y$ be Banach spaces, and let $P$ and $Q$ be Gateaux differentiable mappings from $B(0 ; K) \subseteq X(K>0$, possibly $K=$ $\infty)$ to $Y$. Let $c:[0, K) \rightarrow(0, \infty)$ be a continuous function. Suppose for each $x \in B(0 ; K)$, that

(a) $d Q_{x}$ is a bounded linear operator from $X$ to $Y$, and

(b) $d P_{x}(\bar{B}(0 ; 1)) \supseteq \bar{B}(0 ; c(\|x\|))$.

Suppose in addition, for some $\mu \in(0,1)$ and each $x \in X$ that

(c) $c(\|x\|)^{-1}\left\|d Q_{x}\right\|<\mu$.

If the mapping $R=P+Q$ has closed graph, then $R(B(0 ; K))$ contains $B\left(R(0) ;(1-\mu) \int_{0}^{K} c(s) d s\right)$, in particular $R$ is an open mapping. And if $\int_{0}^{K} c(s) d s=\infty$, then $R(B(0 ; K))=Y$.

In the same situation of Theorem 3.6 Ray and Walker [14] showed that if $P$ and $Q$ have closed graphs, then so does $P+Q$. In [14], in order to prove that $R$ is an open mapping, they used actually the Brezis and Browder principle [2], which was recently generalized in [1] and [18]. However, our Theorem 3.6 can be proved by using only Theorem 2.2 (actually Theorem 2.1 by assuming that $c$ is a constant function) and combining Theorem 3.4, and it gives a precise estimation of range of operators.

\section{REFERENCES}

[1] M. Altman, A generalization of the Brezis-Browder principle on ordered sets, Nonlinear Analysis, TMA., 6 (1982), 157-165.

[2] H. Brezis and F. E. Browder, A general principle on ordered sets in nonlinear functional analysis, Advances in Math., 21 (1976), 355-364.

[3] F. E. Browder, Normal solvability and $\phi$-accretive mappings of Banach spaces, Bull. Amer. Math. Soc., 78 (1972), 186-192. 
[4] Nonlinear operators and nonlinear equations of evolution in Banach spaces, Proc. Symp. Pure Math. Vol. 118, part 2, Amer. Math. Soc., Providence, RI, 1976.

[5] J. Caristi, Fixed point theorems for mappings satisfying inwardness conditions, Trans. Amer. Math. Soc., 215 (1976), 241-251.

[6] W. J. Cramer, Jr. and W. O. Ray. Solvability of nonlinear operator equations, Pacific J. Math., 95 (1981), 37-50.

[7] D. J. Downing and W. O. Ray, Renorming and the theory of phi-accretive set-valued mappings, Pacific J. Math., 106 (1983), 73-85.

[8] I. Ekeland, Sur les problems variationnels, Compte Rendus Acad. Soc. Paris, 275 (1972), 1057-1059.

[9] _ Nonconvex minimization problems, Bull. Amer. Math. Soc., 1 (1976), 443-474.

[10] J. A. Park and S. Park, Surjectivity of $\phi$-accretive operators, Proc. Amer. Math. Soc., 80 (1984), 289-292.

[11] S. Park and J. S. Bae, On the Ray-Walker extension of the Caristi-Kirk fixed point theorem, to appear in Nonlinear Analysis, TMA.

[12] W. O. Ray, Normally solvable nonlinear operators, Contemp. Math., 18 (1983), 155-165.

[13] W. O. Ray and A. M. Walker, Mapping theorems for Gateaux differentiable and accretive operators, Nonlinear Analysis, TMA., 6 (1982), 423-433.

[14] __ Perturbations of normally solvable nonlinear operators, to appear.

[15] I. Rosenholtz and W. O. Ray, Mapping theorems for differentiable operators, Bull. Acad. Polon. Sci. Ser. Math. Aston. Phys., 29 (1981), 265-273.

[16] R. Schöneberg, On the domain invariance theorem for accretive mappings, J. London Math. Soc., 24 (1981), 548-554.

[17] R. Torrejon, $A$ note on locally expansive and locally accretive operators, Canad. Math. Bull., 26 (1983), 228-232.

[18] M. Turinici, A generalization of Altman's ordering principle, Proc. Amer. Math. Soc., 90 (1984), 128-132.

Received June 22, 1985. Partially supported by a grant from the Korea Science and Engineering Foundation, 1984-5.

\section{Chungnam National University}

DAEJEON 300-31, KOREA

AND

SOONG JUN UNIVERSITY

SEOUl 151, KOREA 


\title{
PACIFIC JOURNAL OF MATHEMATICS \\ EDITORS
}

\author{
V. S. VARADARAJAN \\ (Managing Editor) \\ University of California \\ Los Angeles, CA 90024 \\ HERBERT CLEMENS \\ University of Utah \\ Salt Lake City, UT 84112 \\ R. FINN \\ Stanford University \\ Stanford, CA 94305
}

\author{
HERMANN FLASCHKA \\ University of Arizona \\ Tucson, AZ 85721
}

RAMESh A. GANGOLLI

University of Washington Seattle, WA 98195

VAUGHAN F. R. JONES

University of California

Berkeley, CA 94720

ROBION KIRBY

University of California

Berkeley, CA 94720
C. C. MOORE

University of California

Berkeley, CA 94720

H. SAMELSON

Stanford University

Stanford, CA 94305

HAROLD STARK

University of California, San Diego

La Jolla, CA 92093

\section{ASSOCIATE EDITORS}

\author{
R. ARENS \\ E. F. BECKENBACH \\ B. H. NeUmanN \\ F. WOLF \\ K. YOSHIDA \\ (1906-1982)

\section{SUPPORTING INSTITUTIONS} \\ UNIVERSITY OF ARIZONA \\ UNIVERSITY OF BRITISH COLUMBIA \\ CALIFORNIA INSTITUTE OF TECHNOLOGY \\ UNIVERSITY OF CALIFORNIA \\ MONTANA STATE UNIVERSITY \\ UNIVERSITY OF NEVADA, RENO \\ NEW MEXICO STATE UNIVERSITY \\ OREGON STATE UNIVERSITY \\ UNIVERSITY OF OREGON \\ UNIVERSITY OF SOUTHERN CALIFORNIA \\ STANFORD UNIVERSITY \\ UNIVERSITY OF HAWAII \\ UNIVERSITY OF TOKYO \\ UNIVERSITY OF UTAH \\ WASHINGTON STATE UNIVERSITY \\ UNIVERSITY OF WASHINGTON
}

The Supporting Institutions listed above contribute to the cost of publication of this Journal, but they are not owners or publishers and have no responsibility for its content or policies.

Mathematical papers intended for publication in the Pacific Journal of Mathematics should be in typed form or offset-reproduced (not dittoed), double spaced with large margins. Please do not use built up fractions in the text of the manuscript. However, you may use them in the displayed equations. Underline Greek letters in red, German in green, and script in blue. The first paragraph must be capable of being used separately as a synopsis of the entire paper. In particular it should contain no bibliographic references. Please propose a heading for the odd numbered pages of less than 35 characters. Manuscripts, in triplicate, may be sent to any one of the editors. Please classify according to the scheme of Math. Reviews, Index to Vol. 39. Supply name and address of author to whom proofs should be sent. All other communications should be addressed to the managing editor, or Elaine Barth, University of California, Los Angeles, California 90024.

There are page-charges associated with articles appearing in the Pacific Journal of Mathematics. These charges are expected to be paid by the author's University, Government Agency or Company. If the author or authors do not have access to such Institutional support these charges are waived. Single authors will receive 50 free reprints; joint authors will receive a total of 100 free reprints. Additional copies may be obtained at cost in multiples of 50 .

The Pacific Journal of Mathematics is issued monthly as of January 1966. Regular subscription rate: $\$ 190.00$ a year (5 Vols., 10 issues). Special rate: $\$ 95.00$ a year to individual members of supporting institutions.

Subscriptions, orders for numbers issued in the last three calendar years, and changes of address should be sent to Pacific Journal of Mathematics, P.O. Box 969, Carmel Valley, CA 93924, U.S.A. Old back numbers obtainable from Kraus Periodicals Co., Route 100, Millwood, NY 10546.

The Pacific Journal of Mathematics at P.O. Box 969, Carmel Valley, CA 93924 (ISSN 0030-8730) publish'es 5 volumes per year. Application to mail at Second-class postage rates is pending at Carmel Valley, California, and additional mailing offices. Postmaster: send address changes to Pacific Journal of Mathematics, P.O. Box 969, Carmel Valley, CA 93924.

PUBLISHED BY PACIFIC JOURNAL OF MATHEMATICS, A NON-PROFIT CORPORATION

Copyright (C) 1986 by Pacific Journal of Mathematics 


\section{Pacific Journal of Mathematics}

\section{Vol. 125, No. $2 \quad$ October, 1986}

Dale Edward Alspach, On $\mathscr{L}_{p, \lambda}$ spaces for small $\lambda \ldots \ldots \ldots \ldots \ldots \ldots 257$

Jong Sook Bae and Sangsuk Yie, Range of Gateaux differentiable operators

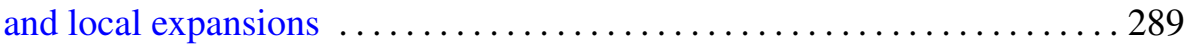

Hubert Berens and Lothar Hetzelt, On accretive operators on $l_{n}^{\infty} \ldots \ldots 301$

Marie-Françoise Bidaut-Véron, Global existence and uniqueness results for singular solutions of the capillarity equation ................. 317

Donald M. Davis and Mark Mahowald, Classification of the stable homotopy types of stunted real projective spaces ................. 335

Aad Dijksma, Heinz K. Langer and Hendrik S. V. de Snoo, Unitary

colligations in $\Pi_{\kappa}$-spaces, characteristic functions and Štraus extensions

Michel Enock and Jean-Marie Schwartz, Algèbres de Kac

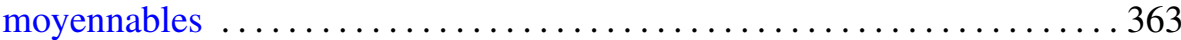

Seppo Granlund, Peter Lindqvist and Olli Martio, Note on the

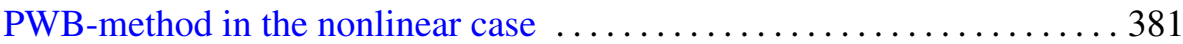

Palle E. T. Jorgensen, Analytic continuation of local representations of Lie

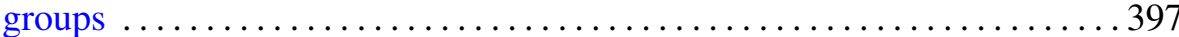

Robert P. Kaufman, Plane curves and removable sets ................409

José M. Montesinos and Wilbur Carrington Whitten, Constructions of two-fold branched covering spaces $\ldots \ldots \ldots \ldots \ldots$.

Benedict Seifert, Highly transitive group actions on trees and normalizing Tits systems

Charles Stuart Stanton, Counting functions and majorization for Jensen

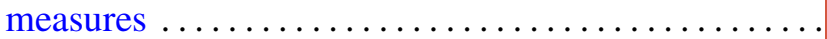

Luen-Fai Tam, On existence criteria for capillary free surfaces without gravity

Zhuocheng Yang, Exposed points of left invariant means 